\title{
Relationship between D-dimer Levels and the Glomerular Filtration Rate in Patients with Chronic Kidney Disease
}

\author{
Vida Sheikh ${ }^{1}$, Nader Ahmadpour-Saheb ${ }^{2}$, Salman Khazaei ${ }^{3, *}$
}

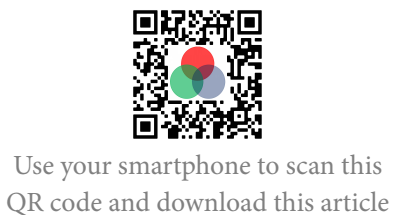

${ }^{1}$ Department of Internal Medicine, School of Medicine, Shahid Beheshti Medical Educational Center, Hamadan University of Medical Sciences, Hamadan, Iran

${ }^{2}$ Student Research Committee, Hamadan University of Medical Sciences, Hamadan, Iran

${ }^{3}$ Research Center for Health Sciences, Hamadan University of Medical Sciences, Hamadan, Iran

\section{Correspondence}

Salman Khazaei, Research Center for Health Sciences, Hamadan University of Medical Sciences, Hamadan, Iran

Email: salman.khazaei61@gmail.com

History

- Received: Aug 29, 2021

- Accepted: Nov 17, 2021

- Published: Nov 30, 2021

DOI : 10.15419/bmrat.v8i11.706

\section{Check for updates}

\section{Copyright}

(c) Biomedpress. This is an openaccess article distributed under the terms of the Creative Commons Attribution 4.0 International license.

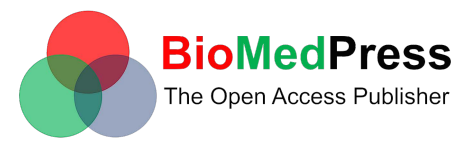

\begin{abstract}
Background: Given the high sensitivity of the D-dimer assessment when ruling out pulmonary embolism, the present study was conducted to investigate the D-dimer levels in patients with CKD based on their related GFR. Methods: The present cross-sectional study included 98 patients with CKD who presented to the nephrology clinic of the Shahid Beheshti Hospital in Hamadan, Iran. The patients gave informed consent before enrollment. The data of each patient was recorded in the form of a checklist. The data analysis was performed using the SPSS software at a significance level of $0.05 \%$. Results: There was found to be a negative correlation between GFR and D-dimer levels in the study participants. However, there was no evidence of thromboembolic events during the 1 -year follow-up. Moreover, we found a direct relationship between patient age and the serum levels of the D-dimer, in that the D-dimer levels were higher in the participants who were older. Conclusion: We concluded that serum D-dimer level has a positive correlation with age, while it has a negative correlation with GFR in CKD patients. However, no evidence of thromboembolic events was found.
\end{abstract}

Key words: Chronic Renal Failure, D-dimer, Dialysis, Glomerular Filtration Rate

\section{INTRODUCTION}

Chronic Kidney Disease (CKD) is defined as a structural defect or decreased function of the kidney ${ }^{1}$. This disorder is diagnosed by having at least one of the following criteria: a Glomerular Filtration Rate (GFR) of $<60 \mathrm{ml} / \mathrm{min} / 1.73 \mathrm{~m}^{2}$, albuminuria, disturbances in urinary sedimentation, histologic or imaging evidence of renal injury, renal tubular disorders, and a history of renal transplantation for longer than 3 months 2,3 .

Glomerular filtration is the process in which the blood passes from a glomerular capillary tuft inside the Bowman's capsule where it is cleared of waste products. However, erythrocytes, leukocytes, and plasma proteins are exceptions, so they remain inside the ves-

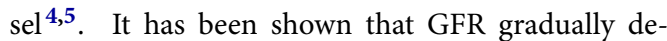
creases with age. This reduction is affected by diet, muscular mass, gender, and race $^{6}$. Based on the GFR, CKD is classified into 5 stages from mild to an advanced disease with End-Stage Renal Disease (ESRD) being the final stage. This is characterized by dramatically reduced GFR and a need for dialysis. In this stage, either peritoneal dialysis or hemodialysis is selected for the patient depending on their condition $^{7-11}$.

D-dimer, one of the molecules that results from fibrin degradation, is very low in the blood of healthy individuals. As an indicator of increased fibrinolysis, elevated levels of D-dimer indicate intravascular coagulation and thrombotic disease. Given its high sensitivity and negative predictive value, D-dimer testing is routinely used in clinical practice as a primary assessment for patients with suspected VTE ${ }^{12,13}$. A negative D-dimer test can definitely rule out VTE. Thus, there is no need for subsequent imaging and anticoagulant therapy ${ }^{13,14}$. Although D-dimer is almost always elevated in VTE, it can also increase due to several other conditions including acute illness, recent trauma or surgery, active malignancies, severe atherosclerosis, and pregnancy, leading to its relatively low specificity and positive predictive value ${ }^{15}$. Moreover, the specificity of D-dimer testing for the VTE diagnosis is even lower in patients with mild or moderate CKD. In these patients, the D-dimer level is associated with the CKD stage and disease progression $^{\mathbf{1 6}}$, therefore positive D-dimer results have no definite diagnostic value for ESRD patients under hemodialysis ${ }^{17}$ because they often have several other comorbidities such as atherosclerosis and malignancy which are also associated with increased serum Ddimer levels ${ }^{\mathbf{1 8}, 19}$. In addition, investigations have shown that the specificity of D-dimer testing for pulmonary embolism diagnosis is significantly reduced in CKD patients because the $\mathrm{D}$-dimer levels are associated with the CKD stage ${ }^{16}$. Therefore, the present 
study aimed to investigate the serum $\mathrm{D}$-dimer level and its relationship with GFR in patients with CKD.

\section{METHODS}

The present cross-sectional study included 98 patients with the diagnosis of CKD who presented to the nephrology clinic of Shahid Beheshti Hospital in Hamadan, Iran from April 2019 to February 2021. The exclusion criteria were active malignancy, rheumatoid arthritis, systemic lupus erythematosus, sickle cell anemia, current history of thromboembolic events, pregnancy, post-partum conditions, recent abdominal, thoracic or orthopedic surgery, cocaine use, hemoptysis, thrombophilia, and a history of trauma in the last 4 weeks. The present study was approved by the Ethics Committee of the Hamadan University of Medical Sciences with the ethics code of IR.UMSHA.REC.1398.869.

The participants gave informed written consent. They then gave blood samples, which were used to proceed with a quantitative D-dimer assessment using the ELFA VIDAS kits by the Biomerieux Company. The cut-off value was $500 \mathrm{ng} / \mathrm{ml}$ for a quantitative Ddimer assessment. The GFR of the participants was calculated using the MDRD formula and their serum creatinine levels, which were obtained from the recent test results of the patients. The patients were classified into 2 groups based on the calculated GFR as follows:

1. Moderate renal failure: $30 \leq \mathrm{GFR} \leq 59$

2. Severe renal failure: GFR $\leq 29$

The clinical and demographic data of the participants, including age, gender, educational level, BMI, the cause of renal failure, serum creatinine, $\mathrm{D}$-dimer level, GFR, and CKD duration were recorded in the related checklists.

Data analysis was performed using the SPSS-24 software with a significance level of $0.05 \%$. The Pearson's correlation, Spearman's correlation, t-test, and MannWhitney $U$ test were used in the analytical part of this study.

\section{RESULTS}

The present study investigated 98 patients diagnosed with CKD. According to our results, $52.04 \%$ of the participants were men. The mean $\pm \mathrm{SD}$ of the participants' age was $58.14 \pm 15.89$ years with a range of $27-93$. More than half of the patients were older than 60 , and most of them were illiterate or had less than a high school diploma. Regarding BMI, 42.86\% had a BMI of $18.5-25 \mathrm{~kg} / \mathrm{m}^{2}$ (Table 1). In total, 52 (53.06\%) patients were undergoing hemodialysis. The most common cause of renal failure was hypertension (45.92\%), followed by diabetes (22.45\%) (Table 2 ). The mean \pm SD values of serum creatinine and $\mathrm{D}$ dimer levels were $4.96 \pm 3.34 \mathrm{mg} / \mathrm{dl}$ and $1614.28 \pm$ $1917.39 \mathrm{ng} / \mathrm{ml}$, respectively. Moreover, the mean \pm SD value for GFR was $20.27 \pm 15.32 \mathrm{ml} / \mathrm{min} .1 .73 \mathrm{~m}^{2}$. The mean \pm SD for CKD duration was $10.36 \pm 6.54$. Finally, for a total 98 participants, 75 (76.53\%) had a positive D-dimer test, while $23(23.47 \%)$ had a negative test.

The serum D-dimer level had a significant positive correlation with creatinine and age $(\mathrm{P}<0.05)$, while it had a significant negative correlation with GFR $(\mathrm{P}<$ 0.05). Moreover, there was a significant negative correlation between GFR and creatinine level (Table 3). Using the Mann-Whitney U test, we found a significant difference between the patients with moderate $(30 \leq \mathrm{GFR} \leq 59)$ and severe (GFR $\leq 29) \mathrm{CKD}$ and the $\mathrm{D}$-dimer levels $(986.37 \pm 943.68$ vs. $1853.06 \pm$ 2133.95, $\mathrm{P}=0.024)$.

\section{DISCUSSION}

According to our results, there was a significant relationship between serum D-dimer level and the patients' GFR and age. We also found a negative correlation between GFR and serum D-dimer level. Patients with a lower GFR had higher D-dimer levels. In addition, there was a direct correlation between age and serum D-dimer level, meaning that an increased age led to higher D-dimer levels.

The present study is compatible with most similar studies $^{20-24}$. For example, a study by Robert-Ebadi et al. on 1,625 participants found a more significant relationship between D-dimer level and GFR in patients whose possibility of pulmonary embolism had been ruled out compared to those with a diagnosis of pulmonary embolism ${ }^{23}$. In a study of 1305 participants, 169 participants (13\%) were affected by pulmonary embolism, Linder et al. showed there to be a significant relationship between the calculated GFR and D-dimer level ${ }^{21}$. A study by Gubensek et al. on 167 participants undergoing chronic hemodialysis reported a mean D-dimer level of $966 \mathrm{ng} / \mathrm{ml}$ in these patients. Moreover, $75 \%$ of the patients had a positive $\mathrm{D}$-dimer test (> $500 \mathrm{ng} / \mathrm{ml}$ ), and the $\mathrm{D}$-dimer levels were significantly correlated with the participants' age $^{25}$. These results are compatible with our results. According to a study by Xi et al. involving 1784 participants, the mean D-dimer levels were $291.5 \mathrm{mg} / \mathrm{L}$, $995.5 \mathrm{mg} / \mathrm{L}$, and $1901.5 \mathrm{mg} / \mathrm{L}$ in the patients with normal renal function, mild renal disease, and moderate renal disease, respectively. They found a significant relationship between D-dimer level and GFR ${ }^{24}$. 
Table 1: Demographicsof the patients diagnosed with CKD

\begin{tabular}{llcc}
\hline Variable & Sub-groups & Frequency & Percentage (\%) \\
\hline Age group (year) & Younger than 45 & 19 & 19.39 \\
& $45-60$ & 28 & 28.57 \\
& Older than 60 & 51 & 52.04 \\
Gender & Men & 51 & 52.04 \\
Women & 47 & 47.96 \\
Educatioal level & Illiterate & 34 & 34.69 \\
& Lower than the high school & 41 & 41.84 \\
& High school and diploma & 12 & 12.24 \\
BMI $\left(\mathrm{kg} / \mathrm{m}^{2}\right)$ & Academic & 11 & 11.22 \\
& BMI $\leq 18.5$ & 3 & 3.06 \\
& $18.5<\mathrm{BMI} \leq 25$ & 42 & 42.86 \\
& $25<\mathrm{BMI} \leq 30$ & 34 & 34.69 \\
& $30<\mathrm{BMI}$ & 19 & 19.39 \\
\hline
\end{tabular}

Table 2: Frequency distribution of renal failure causes in patients with CKD

\begin{tabular}{lcc}
\hline CKD cause & Frequency & Percentage (\%) \\
\hline Diabetes & 22 & 22.45 \\
Hypertension & 45 & 45.92 \\
Nephrolithiasis and other urologic disorders & 12 & 12.24 \\
Polycystic kidney disease & 10 & 10.20 \\
Glomerulonephritis & 5 & 5.10 \\
Collagen-vascular diseases & 2 & 2.04 \\
Cardiorenal diseases & 2 & 2.04 \\
\hline
\end{tabular}

Table 3: Relationships between the study variables in patients with CKD

\begin{tabular}{|c|c|c|c|c|c|c|}
\hline & & D-dimer & Creatinine & GFR & Age & CKD duration \\
\hline \multirow[t]{2}{*}{ D-dimer } & $\mathrm{R}$ & 1 & - & - & - & - \\
\hline & P-value & & & & & \\
\hline \multirow[t]{2}{*}{ Creatinine } & $\mathrm{R}$ & 0.1661 & 1 & - & - & - \\
\hline & P-value & 0.1021 & & & & \\
\hline \multirow[t]{2}{*}{ GFR } & $\mathrm{R}$ & -0.2975 & -0.8234 & 1 & - & - \\
\hline & P-value & $0.0029^{*}$ & $0.0000^{*}$ & & & \\
\hline \multirow[t]{2}{*}{ Age } & $\mathrm{R}$ & 0.2096 & -0.0973 & -0.0100 & 1 & - \\
\hline & P-value & $0.0383^{*}$ & 0.3403 & 0.9224 & & \\
\hline \multirow{2}{*}{$\begin{array}{l}\text { CKD } \\
\text { duration }\end{array}$} & $\mathrm{R}$ & 0.1749 & 0.0540 & -0.1398 & 0.0986 & 1 \\
\hline & P-value & 0.0849 & 0.5975 & 0.1697 & 0.3338 & \\
\hline
\end{tabular}

${ }^{*}$ P-value $<0.05$ 
Huang et al. performed a study on 115 participants and found a significantly elevated D-dimer level in patients with CKD stages 3, 4, and $5^{20}$.

Mohammed and Khalil performed a study on 49 patients with CKD and found there to be no significant relationship between D-dimer level and the patients' GFR and age. They reported a significant correlation between D-dimer level and CKD duration ${ }^{22}$.

The present study had some limitations. For example, our sample size was smaller than similar studies due to the limited financial resources. Moreover, some patients refused to participate due to the invasive sampling method used.

\section{CONCLUSIONS}

According to our results, there was a significant correlation between the serum D-dimer level and the patients' GFR and age in patients with CKD, including those affected by ESRD who underwent hemodialysis. Given the present study results, we recommend setting a GFR-adjusted cut-off for D-dimer testing in patients with GFR $<60 \mathrm{ml} / \mathrm{min} .1 .73 \mathrm{~m}^{2}$ to reduce the number of false-positive results. The patients with CKD will be less exposed to imaging modalities with contrast which may lead to contrast-related nephropathy, exacerbating the current renal dysfunction of the patients.

\section{ABBREVIATIONS}

BMI: Body Mass Index

CKD: Chronic Kidney Disease

ESRD: End-Stage Renal Disease

GFR: Glomerular Filtration Rate

SD: Standard Deviation

VTE: Venous Thromboembolism

\section{ACKNOWLEDGMENTS}

This article was derived from a research project approved by the Esfarayen University of Medical Sciences, which was conducted with the financial support of this university. The researchers would like to express their gratitude to the University Research Council and all patients, who participated in this study.

\section{AUTHOR'S CONTRIBUTIONS}

VS, SK, and NAS developed the original idea and the protocol, abstracted, and prepared the manuscript. SK and VS participated in the study design and analyzed the data. VS, and NAS contributed to the data gathering. All authors read and approved the final manuscript.

\section{FUNDING}

This study was funded by the Hamadan University of Medical Sciences, Iran (Research ID: 9811158772).

\section{AVAILABILITY OF DATA AND MATERIALS}

Data and materials used and/or analysed during the current study are available The data that support the findings of the study are available from the corresponding author in SPSS form upon reasonable request.

\section{ETHICS APPROVAL AND CONSENT TO PARTICIPATE}

This study was conducted in accordance with the amended Declaration of Helsinki. Institutional review board approval was obtained from the ethics committees of Hamadan University of Medical Sciences (Ethics code: IR.UMSHA.REC.1398.869), and all participants provided written informed consent.

\section{CONSENT FOR PUBLICATION}

Not applicable.

\section{COMPETING INTERESTS}

The authors declare that they have no competing interests.

\section{REFERENCES}

1. Kellum JA, Lameire N, Aspelin P, Barsoum RS, Burdmann EA, Goldstein SL. Kidney disease: improving global outcomes (KDIGO) acute kidney injury work group. KDIGO clinical practice guideline for acute kidney injury. Kidney International Supplement. 2012;2(1):1-138.

2. Chen TK, Knicely DH, Grams ME. Chronic kidney disease diagnosis and management: a review. Journal of the American Medical Association. 2019;322(13):1294-304. PMID: 31573641. Available from: 10.1001/jama.2019.14745.

3. Romagnani P, Remuzzi G, Glassock R, Levin A, Jager KJ, Tonelli M. Chronic kidney disease. Nature Reviews Disease Primers. 2017;3(1):17088. PMID: 29168475. Available from: 10.1038/ nrdp.2017.88.

4. Levey AS, Becker C, Inker LA. Glomerular filtration rate and albuminuria for detection and staging of acute and chronic kidney disease in adults: a systematic review. Journal of the American Medical Association. 2015;313(8):837-46. PMID: 25710660. Available from: 10.1001/jama.2015.0602.

5. Renkin EM, Robinson RR. Glomerular filtration. The New England Journal of Medicine. 1974;290(14):785-92. PMID: 4592673. Available from: 10.1056/NEJM197404042901408.

6. Stevens LA, Coresh J, Greene T, Levey AS. Assessing kidney function measured and estimated glomerular filtration rate. The New England Journal of Medicine. 2006;354(23):2473-83. PMID: 16760447. Available from: 10.1056/NEJMra054415.

7. Inker LA, Schmid CH, Tighiouart $\mathrm{H}$, Eckfeldt JH, Feldman $\mathrm{HI}$, Greene $\mathrm{T}$, et al. Estimating glomerular filtration rate from serum creatinine and cystatin C. The New England Journal of Medicine. 2012;367(1):20-9. PMID: 22762315. Available from: 10.1056/NEJMoa1114248. 
8. Eknoyan G, Lameire N, Eckardt K, Kasiske B, Wheeler D, Levin A. KDIGO 2012 clinical practice guideline for the evaluation and management of chronic kidney disease. Kidney International. 2013;3(1):5-14.

9. Inker LA, Grams ME, Levey AS, Coresh J, Cirillo M, Collins JF, et al. Relationship of estimated GFR and albuminuria to concurrent laboratory abnormalities: an individual participant data meta-analysis in a global consortium. American Journal of Kidney Diseases. 2019;73(2):206-17. PMID: 30348535. Available from: 10.1053/j.ajkd.2018.08.013.

10. Wattanakit K, Cushman M. Chronic kidney disease and venous thromboembolism: epidemiology and mechanisms. Current Opinion in Pulmonary Medicine. 2009;15(5):408-12. PMID: 19561505. Available from: 10.1097/MCP.0b013e32832ee371.

11. Bounameaux $H$, de Moerloose $P$, Perrier A, Reber G. Plasma measurement of $\mathrm{D}$-dimer as diagnostic aid in suspected venous thromboembolism: an overview. Thrombosis and Haemostasis. 1994;71(1):1-6. PMID: 8165626. Available from: 10.1055/s-0038-1642375.

12. Brill-Edwards $P$, Lee $A$. D-dimer testing in the diagnosis of acute venous thromboembolism. Thrombosis and Haemostasis. 1999;82(2):688-94. PMID: 10605769.

13. Bates SM, Jaeschke R, Stevens SM, Goodacre S, Wells PS, Stevenson MD. Diagnosis of DVT: antithrombotic therapy and prevention of thrombosis: American College of Chest Physicians evidence-based clinical practice guidelines. Chest. 2012;141(2):e351-418. PMID: 22315267. Available from: 10. 1378/chest.11-2299.

14. van Belle A, Büller HR, Huisman MV, Huisman PM, Kaasjager $\mathrm{K}$, Kamphuisen PW, et al. Effectiveness of managing suspected pulmonary embolism using an algorithm combining clinical probability, D-dimer testing, and computed tomography. Journal of the American Medical Association. 2006;295(2):172-9. PMID: 16403929. Available from: 10.1001/ jama.295.2.172.

15. Stein PD, Hull RD, Patel KC, Olson RE, Ghali WA, Brant R. Ddimer for the exclusion of acute venous thrombosis and pulmonary embolism: a systematic review. Annals of Internal Medicine. 2004;140(8):589-602. PMID: 15096330. Available from: 10.7326/0003-4819-140-8-200404200-00005.

16. Karami-Djurabi R, Klok FA, Kooiman J, Velthuis SI, Nijkeuter M, Huisman MV. D-dimer testing in patients with suspected pulmonary embolism and impaired renal function. The American
Journal of Medicine. 2009;122(11):1050-3. PMID: 19698934 Available from: 10.1016/j.amjmed.2009.03.032.

17. Miozzari $M$, Wahl C. D-dimers in hemodialysis patients. The Nephron Journals. 2001;88(3):278-9. PMID: 11423763. Available from: $10.1159 / 000046004$.

18. Ambühl PM, Wüthrich RP, Korte W, Schmid L, Krapf R. Plasma hypercoagulability in haemodialysis patients: impact of dialysis and anticoagulation. Nephrology, Dialysis, Transplantation. 1997;12(11):2355-64. PMID: 9394323. Available from: 10.1093/ndt/12.11.2355.

19. Milburn JA, Cassar K, Ford I, Fluck N, Brittenden J. Prothrombotic changes in platelet, endothelial and coagulation function following hemodialysis. The International Journal of Artificial Organs. 2011;34(3):280-7. PMID: 21445833. Available from: 10.5301/IJAO.2011.6469.

20. Huang MJ, Wei RB, Wang Y, Su TY, Di P, Li QP. Blood coagulation system in patients with chronic kidney disease: a prospective observational study. BMJ Open. 2017;7(5):e014294. PMID: 28576889. Available from: 10.1136/ bmjopen-2016-014294.

21. Lindner G, Funk GC, Pfortmueller CA, Leichtle $A B$, Fiedler $\mathrm{GM}$, Schwarz C. D-dimer to rule out pulmonary embolism in renal insufficiency. The American Journal of Medicine. 2014;127(4):343-7. PMID: 24355353. Available from: 10.1016/ j.amjmed.2013.12.003.

22. Mohammed NM, Khalil HB. D-dimer levels in patients presenting chronic kidney disease in Sudan. American Journal of Medicine and Medical Sciences. 2016;120:2-6.

23. Robert-Ebadi H, Bertoletti L, Combescure C, Gal GL, Bounameaux $H$, Righini $M$. Effects of impaired renal function on levels and performance of D-dimer in patients with suspected pulmonary embolism. Thrombosis and Haemostasis. 2014;112(3):614-20. PMID: 24898973.

24. Xi X. Potential effect of a renal function adjusted D-dimer cutoff value to improve the exclusion of pulmonary embolism Chest. 2016;149(4):524. Available from: 10.1016/j.chest.2016. 02.546 .

25. Gubensek J, Lolic M, Ponikvar R, Buturovic-Ponikvar J. D-dimer levels in maintenance hemodialysis patients: high prevalence of positive values also in the group without predisposing diseases. Hemodialysis International International Symposium on Home Hemodialysis. 2016;20(2):198-203. PMID: 26415880. Available from: 10.1111/hdi.12371. 
Ready to submit your manuscript? Choose Biomedpress and benefit from:

- Fast, convenient online submission

- Through peer-review by experienced researchers

- Rapid publication on acceptance

- Free of charge (without publication fees)

Learn more http://www.biomedpress.org/journals/
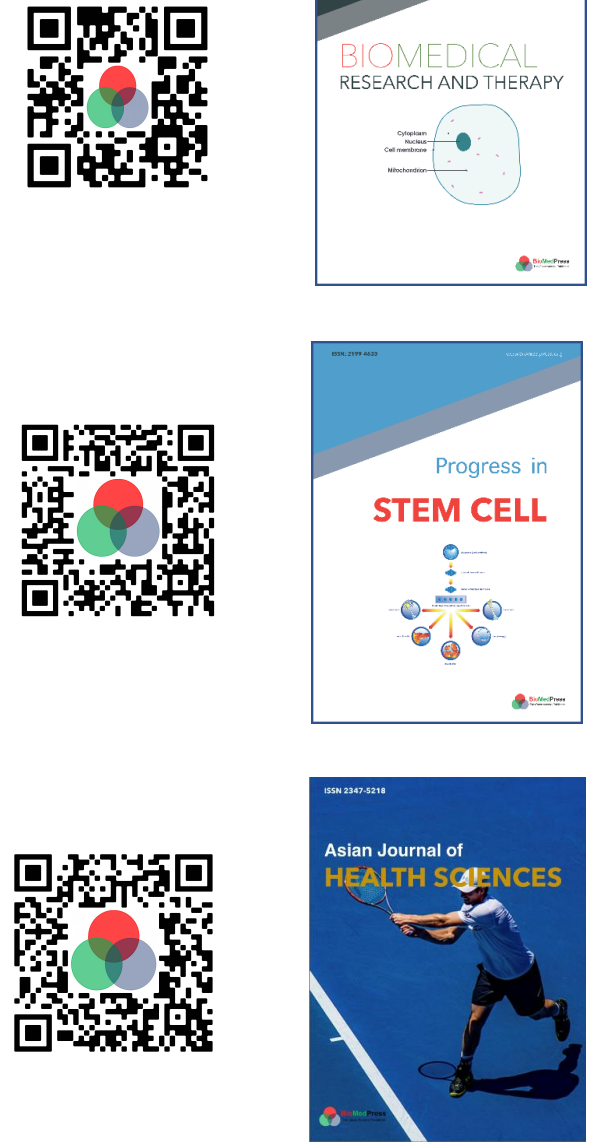

Asian Journal of Health Sciences

ISSN: 2347-5218

Indexed: Google Scholar

Acceptance Rate (2020): 72.89\%

Article Publishing Charge: Free

Submission to first editorial decision: 16.5 days

Biotechnological Research

ISSN: 2395-6763

Indexed: Google Scholar

Acceptance Rate (2020): $67.02 \%$

Article Publishing Charge: Free

Submission to first editorial decision: 28.5 days 